\title{
The Research on the Effects of Apparel Industrial Cluster of Brand Development and Evaluation
}

\author{
Yan Zhang ${ }^{1}$, Silong Jiang ${ }^{1} \&$ Shouzhong $\mathrm{Hu}^{1}$ \\ ${ }^{1}$ Department of Fashion, Shanghai University of Engineering Science, Shanghai, China \\ Correspondence: Shouzhong Hu, College of fashion. Shanghai University of Engineering Science, China. E-mail: \\ hushzh@sues.edu.cn
}

Received: October 9, 2014

Accepted: October 31, 2014

Online Published: November 13, 2014

doi:10.5430/jbar.v4n1p1

URL: http://dx.doi.org/10.5430/jbar.v4n1p1

\begin{abstract}
The industrial cluster brand in China's textile and clothing industry is still in the initial stage, factors affecting the development of industrial cluster brand and how to develop the industrial cluster brand of the textile and clothing industry are very concerned by the enterprises, however, systematic research on the theory isn't perfect. This paper stands the perspective of the initiative of cluster brand to carry on the factor analysis and hypothesis by 5 aspects, and form factors of structural equation model of the textile and clothing industry eventually. After analyzing, estimating and testing the model, I test the hypothesis of the theoretical model, and the results support most hypotheses. This paper aims to make information for textile and clothing enterprises to better understand the influence factor of industry cluster brand development, and take effective measures, which to promoting industry cluster brand development degree.
\end{abstract}

Keywords: Industry cluster brand, Factor of structural equation model, Hypothesis testing

\section{Introduction}

\subsection{The present situation of apparel industrial cluster of brand}

Along with the development of industry economic has entered a new era, timproving competitiveness and sustainable of industry economic become the focus of attention of all regions, Industrial clusters as a relatively new industry model get the attention of many regional governments, Economies of scale that brought about by industrial clusters enhance the competitiveness and sustainable development of the area industry. At the same time, in the economic environment of modern brand, Brand development of industrial clusters is the trend that shifts from the traditional model to modern. Through the study (Wu, J. X., Chen, J. X., Chen, L.H., 2011) (Chen, J. 2007) is not difficult to find that modern industrial cluster is more emphasis on innovation--driven and development of brand economic to traditional industrial cluster and weak the concept of geographical; that more emphasis on the control of whole industry chain and function complementary to get more profits, but weak the economies of scale asset gathering.

The so-called cluster brand is the whole cluster as a brand to be managed and operated, to a certain extent, the brand development of clusters will be conducive to elongation of the both ends of the industrial chain in the enterprise within clusters, in order to further improve the industrial cluster structure, that has a great effect to enhance the level for the industry. Although the textile and garment industry is as a traditional labor--intensive industries, the effect of the cluster brand will drive the whole industry chain level, and the brand development of textile and garment industry cluster will become an inevitable trend. This is only just started in the clothing industry cluster development path currently.

\subsection{The significance of developing the apparel industrial cluster of brand}

(1) The cluster brand is conducive to new growth pole in the cluster development, In today's competitive market, the competition shift from a single enterprise to clusters that having a complete industrial chain and value chain. the cluster brand will attract more resources pour into the cluster, which allow the enterprises to gain new knowledge. Developing to the top of the value chain by innovation, cluster industries continue to extend to the both ends of the industries chain, so as to develop a new growth pole, optimize the value chain of the cluster industries and promote the competitive of the cluster. 
(2) The cluster brand is conducive to appreciate the cluster asset. First of all, the cluster brand is the public asset of the cluster, the enterprise within the cluster share the advantages of the cluster, the cluster brand represent the competitive of whole cluster industries. Secondly, cluster brand help to reduce the extend cost of the famous enterprises brands within the cluster, at the same time, many excellent quality SEM share the intangible asset of the cluster brand. Increasing the added value and reducing the cost of creating a brand, which improve the intangible assets of enterprises and improve the product competitive.

(3) The cluster brand is conducive to enhancing the cluster influence. Brand is the effective via to enhance the social influence whether it is the business or clusters. In the context of economic globalization, the competitive of the cluster industry is close to the cluster brand. The cluster brand is the card of the cluster industry, the development of the cluster brand is the most effective via to enhancing the cluster influence and the market competitive.

\section{The analysis and assumption of cluster brand impacted factors}

First, the formation of cluster brand is the result of the function of a series of factors, the model of cluster brand in different regions is different, the formation of cluster brand is major depend on the interactive of business, government and social environment. This paper stands the perspective of the initiative of cluster brand (enterprise) to explore the factors that affect the development of industries cluster brand. According to the studies (George, A. 2007) (Gao, C. K, Hu, S. Z. 2013) and the relationship analysis between the industries cluster brand and corporate brand, we can get that the corporate brand and cluster brand is interdependent. The formation of cluster brand need the development of the corporate brand, and the "umbrella brand" of the cluster offer the protection to the development of the corporate brand, so the cluster brand and the corporate brand have the inseparable relationship. As a result, the paper defines the impacted factors of cluster brand. That is corporate product, corporate imagination, corporate brand, corporate internet and corporate innovation.

i) Standing on the perspective of enterprise product, conducting the research on the impact of enterprise products to the cluster brand, we choose three aspects, that is the degree of product match, price advantage and the degree of product innovation, to analyze and make the following assumptions:

H1: There is a positive correlation between enterprise product and the development of cluster brand; H11: The degree of product match has a significant relation to the quality of enterprise products; H12: Price advantage has a significant relation to the enterprise products; H13: The degree of product innovation has a significant relation to the enterprise product.

ii) From the perspective of the enterprise image, exploring enterprise image contains three factors: the awareness of enterprise image of consumer, consumer image and the objective image of enterprise. We make the following assumptions for enterprise scale and the development of cluster brand:

$\mathrm{H} 2$ : Enterprise image has a significant relation to the image of the cluster brand; H21: The awareness of enterprise image of consumer has a significant relation to enterprise image; H22: Consumer image has a significant relation to enterprise image; H23: The objective image of enterprise has a significant relation to enterprise image.

iii) The impact on the corporate brand to the cluster brand is mainly reflected at the development of corporate brand, brand image, the effect of joint brand and corporate brand embedded. Based on the impact of the corporate brand to the cluster brand, we make the following assumptions:

H3: There is a positive correlation between the condition of corporate brand and the development of cluster brand; H31: The development of corporate brand has a significant relation to the condition of corporate brand; H32: Brand image has a significant relation to the condition of corporate brand; H33: The effect of joint brand has a significant relation to the condition of corporate brand; H34: Corporate brand embedded has a significant relation to the condition of corporate brand.

iv) Network relation of enterprise within cluster is mainly contains the contact of enterprise and chain integrity, as to the relation between the network of enterprise within cluster and the development of the cluster brand, we make the following assumption:

H4: There is a positive correlation between the network of enterprise and the development of cluster brand; H41: The contact of enterprise has a significant relation to the formation of the network of enterprise; H42: Chain integrity has a significant relation to the development of the network of enterprise.

v) Innovation is the motive of the development of enterprise, the innovation of enterprise is mainly contain three aspects: technology innovation, culture management system innovation and marketing innovation. We make the following assumption for the impact that corporate innovation to the development of cluster brand. 
H5: corporate innovation has a significant relation to the development of the cluster brand; H51: technology innovation has a significant relation to corporate innovation; H52: culture management system innovation has a significant relation to corporate innovation; H53: marketing innovation has a significant relation to corporate innovation.

vi) By studying the brand and cluster with the foregoing analysis, we can find that there are mutual influence between the company product and corporate image and between the corporate network and corporate innovation, no one factor is impact the cluster brand independent. Therefore, we make further assumption in this paper:

H6: corporate product has a significant relation to corporate brand; H7: corporate product has a significant relation to corporate image; H8: corporate brand has a significant relation to corporate image; H9: corporate network has a significant relation to corporate innovation.

\section{The analysis of cluster brand impacted factor}

Before By corporate perspective, we developed a system of indicators of factors to the factors affecting the textile and garment industry cluster brand development, the assumption and analysis and the designation of specific measurement items. (as follows):

\section{Enterprise product V1}

The degree of product match $\mathrm{W} 1$, the measurement items are product image design match (ITEM1), product features match (ITEM2), product quality match (ITEM3), product material match (ITEM4), advertising image match (ITEM5)

Price advantage W2, the measurement items are production R\&D cost advantage (ITEM6), management cost advantage (ITEM7), promotion cost advantage (ITEM8)

The degree of product innovation $\mathrm{W} 3$, the measurement items are materials innovation (ITEM9), product features innovation (ITEM10), craft innovation (ITEM11), technical innovation (ITEM12)

\section{Enterprise image V2}

(1) The awareness of enterprise image of consumer W4, the measurement items are the recognition of enterprise culture of consumer (ITEM13), the recognition of product image of consumer (ITEM14), the focus of enterprise advertising of consumer (ITEM15)

(2) Consumer image W5, the measurement items are the age of consumer (ITEM16), the income of consumer (ITEM17), the degree of education of consumer (ITEM18), the career of consumer (ITEM19)

(3) The objective image of enterprise W6, the measurement items are the sales of company (ITEM20), the market share of company (ITEM21), the number of employees (ITEM22), culture history (ITEM23), technological heritage (ITEM24), company honor (ITEM25)

\section{Corporate brand V3}

The development of corporate brand W7, the measurement items are the total number of corporate brand (ITEM26), the number of famous corporate brand (ITEM27), the awareness of corporate brand of consumer (ITEM28), consumer loyalty (ITEM29)

Brand image w8, the measurement items are consistency of brand culture (TEM30), consistency of brand level (ITEM31), consistency of target consumer (ITEM32)

The effect of joint brand W9, the measurement items are the visibility of joint brand (ITEM33), the innovation of joint brand (ITEM34), the competitive of joint brand (ITEM35)

Corporate brand embedded W10, the measurement items are the fusion of brand and local culture (ITEM36), the fusion of brand and local system (ITEM37)

\section{The Internet of enterprise V4}

The contact of enterprise W11, the measurement items are the cooperation and competition of technology among enterprises (ITEM38), the cooperation and competition of human among enterprises (ITEM39), the cooperation and competition of sale channels among enterprises (ITEM40), the number of common technology among enterprises (ITEM41), the join of upstream and downstream enterprises (ITEM42)

Chain integrity W12, the measurement items are the number of range enterprises within per unit area (ITEM43), the sales ration of enterprises within clusters (ITEM44), the number of enterprises of industry chain within clusters 


\section{(ITEM45)}

\section{Enterprise innovation V5}

Technology innovation W13, the measurement items are the innovation of common technology (ITEM46), core technology innovation (ITEM47)

Culture management system innovation W14, the measurement items are purpose of the enterprise innovation (ITEM48), the management methods innovation (ITEM49), the image of enterprise innovation (ITEM50), the organization structure innovation (ITEM51)

Marketing innovation W15, the measurement items are the marketing methods innovation (ITEM52), the reposition of marketing object (ITEM53), the promotion channels innovation (ITEM54)

Thus, this paper analyses the relationship between factors influencing and cluster brand, then screen the index system of factors, considering the post processed data should be simple and convenient in developing the research plan. This paper mainly adopts Li Kete Seven points scale to analyze by SPSS and AMOS software tools.

We do the validity analysis on survey data tested by SPSS18.0 and eliminated the measurement of factor loading $<0.5$,Such as culling level indicators enterprise brand V3,Measurement of ITEM26, ITEM27;An indicator of innovation V5,Measurement of ITEM50, ITEM51,After eliminating the factor scale then did the validity analysis and find that KMO value of each numerical scale, Bartlett value as well as the factor loadings and the cumulative variance contribution rate and other indicators are in line with the relevant requirements.

\section{Textile and garment industrial cluster brand factors model}

\subsection{Set the textile and garment industry cluster brand structure model}

After Through the validity and reliability of the above data, I established structural equation model of textile and garment industry cluster influencing factors initially (as shown in Figure 1).

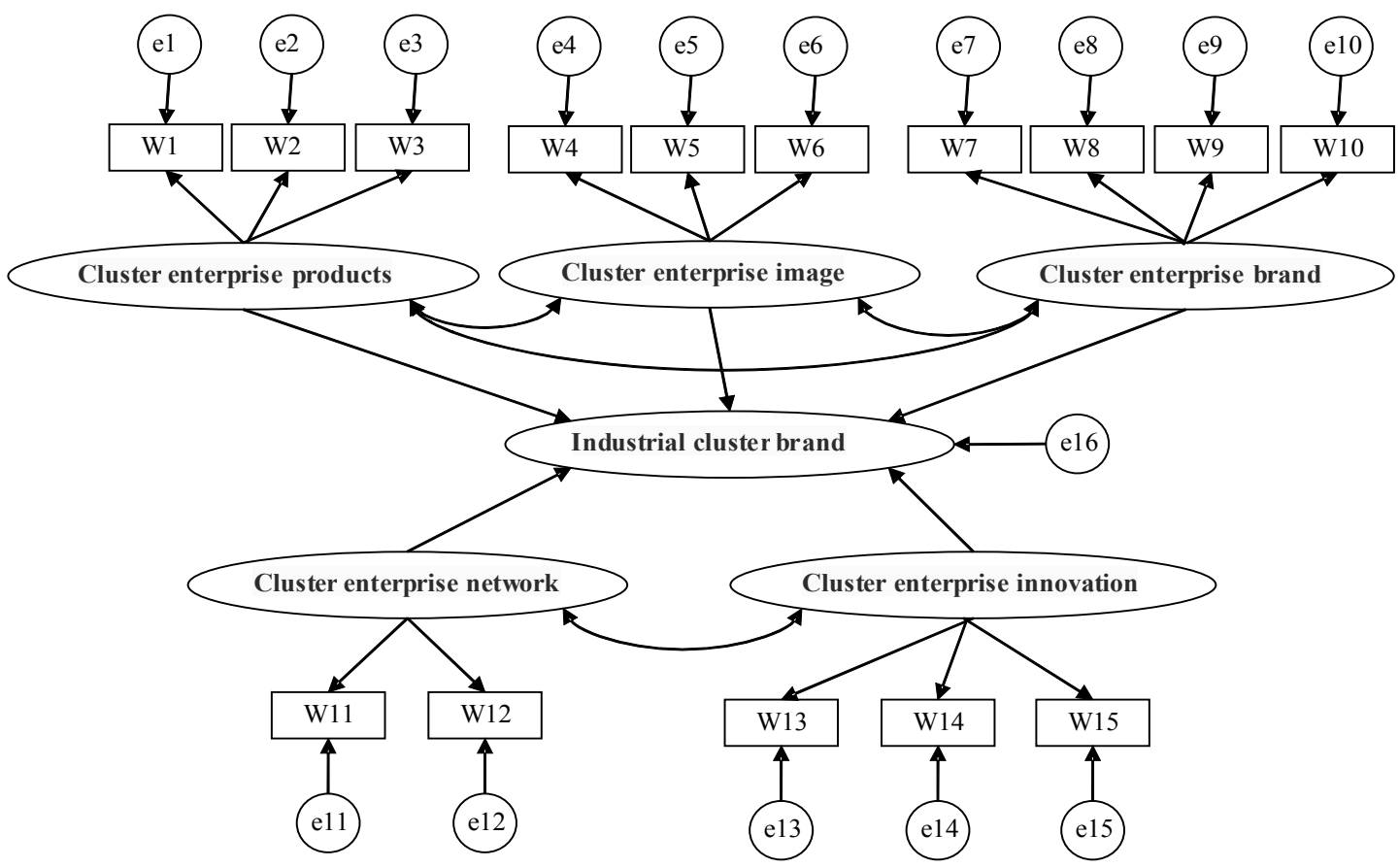

Figure 1. Influencing factors structural equation model diagram

This model mainly involves five exogenous latent variables, they are enterprise product V1, corporate image V2, enterprise brand V3, enterprise network V4, enterprise innovation V5, The V1 contains the observed variables, which are matching degree $\mathrm{W} 1$, price advantage $\mathrm{W} 2$, product innovation $\mathrm{W} 3, \mathrm{~V} 2$ observed variables included in consumers perception of the corporate image W4, consumer image W5, corporate objective image W6, V3 observed variables included in corporate brand development $\mathrm{W} 7$, brand image $\mathrm{W} 8$, joint branding $\mathrm{W} 9$, corporate brand embeddedness W10, V4 observed variables included in the links between enterprisesW11, the industrial chain integrity W12,V5 contains the observation variables of technology innovation W13,cultural management system innovation W14, 
marketing innovation W15, E1-e15 is the error of observation variables. This model contains an internal potential variables that industrial cluster brand, E16 is the residual internal latent variables, In addition, this model also contains four covariance V1, V2, V3, V4, V5 four external latent variables.

4.2 Identification, estimation, and evaluation of structural equation modeling of the factors affecting the textile and garment industry cluster

If want to estimate the various parameters, we must identify the structural equation model, In the identification process of structural equation model, the most commonly used algorithm is $t$ inspection law. The formula is as follows:

$$
\mathrm{t} \leq \frac{1}{2}(p+q)(p+q+1)
$$

According to the rule, only when the freedom degree is more than 0 , the model can be identified, generally speaking, All the model equations model hoped is overidentified models. Only in this way can test the fit of model, In this model, a total of 4 covariance, 20 square, 15 paths of needs analysis, so the location parameter are in $\mathrm{t}=4+20+15=39$ model, In addition, according to the formula:

$$
\frac{1}{2}(p+q)(p+q+1)=120
$$

$\mathrm{t}=39<120$, so, the model is overidentified models.

In this paper, we estimated each parameter in the model by the AMOS17.0 After model identification, we got the path graph structure equation model after estimate the parameter by the ML method, (as shown in Figure 1)

When complete the estimate of structural equation model, fit the test model, Fit index is used to evaluate the path model analysis and data matching criteria. In a structural equation model, mainly from two aspects to evaluate model. One is the model fit index, including the error variance, Factor loadings should between 0.5-- 0.9, The standard error is very small. Two is the overall model fit indicts, Different scholars in the study of the indexes using different indexes, But basically use the indexes of NC, CFI, RMSEA, GFI, RMR,IFI and TLI, By structural equation analysis estimated the output path can be seen, the model matching is reasonable, sample data and assumptionists of the model to achieve a good fit.

\subsection{Testing the hypothesis of the theoretical model}

Through the analysis on the model estimation and test, we need to test the proposed hypothesis, Inspection structure is as follows (see the Table 1):

\begin{tabular}{|c|c|c|c|}
\hline assumptions & Relationships between variables & Path coefficient & Result \\
\hline $\mathrm{H} 1$ & Enterprise products--- Cluster brand & 0.65 & Pass \\
\hline H11 & $\begin{array}{l}\text { Enterprise products--- } \\
\text { Matching degree of products }\end{array}$ & 0.63 & Pass \\
\hline $\mathrm{H} 12$ & $\begin{array}{l}\text { Enterprise products--- Product price } \\
\text { advantage }\end{array}$ & 0.64 & Pass \\
\hline H13 & $\begin{array}{l}\text { Enterprise products--- } \\
\text { Product innovation }\end{array}$ & 0.66 & Pass \\
\hline $\mathrm{H} 2$ & Corporate image--- Cluster brand & 0.63 & Pass \\
\hline $\mathrm{H} 21$ & $\begin{array}{l}\text { Corporate image--- Consumer } \\
\text { awareness of corporate image }\end{array}$ & 0.71 & Pass \\
\hline $\mathrm{H} 22$ & Corporate image--- Consumer image & 0.54 & Pass \\
\hline $\mathrm{H} 23$ & $\begin{array}{l}\text { Corporate image--- Objective image } \\
\text { of enterprise }\end{array}$ & 0.62 & Pass \\
\hline
\end{tabular}

Table 1. Model hypothesis verification results 


\begin{tabular}{|c|c|c|c|}
\hline assumptions & Relationships between variables & Path coefficient & Result \\
\hline $\mathrm{H} 3$ & Enterprise brand--- Cluster brand & 0.68 & Pass \\
\hline $\mathrm{H} 31$ & $\begin{array}{l}\text { Enterprise brand--- The development } \\
\text { of enterprise brand }\end{array}$ & 0.55 & Pass \\
\hline H32 & Enterprise brand--- Brand image & 0.68 & Pass \\
\hline $\mathrm{H} 33$ & $\begin{array}{l}\text { Enterprise brand--- Combined } \\
\text { with the brand effect }\end{array}$ & 0.69 & Pass \\
\hline H34 & $\begin{array}{l}\text { Enterprise brand--- embeddedness of } \\
\text { enterprise brand }\end{array}$ & 0.72 & Pass \\
\hline $\mathrm{H} 4$ & Enterprise network--- Cluster brand & 0.75 & Pass \\
\hline H41 & $\begin{array}{l}\text { Enterprise network--- The links } \\
\text { between enterprises }\end{array}$ & 0.76 & Pass \\
\hline $\mathrm{H} 42$ & $\begin{array}{l}\text { Enterprise network--- Complete } \\
\text { industry chain }\end{array}$ & 0.63 & Pass \\
\hline H5 & $\begin{array}{l}\text { Enterprise innovation--- } \text { Cluster } \\
\text { brand }\end{array}$ & $\begin{array}{l}0.81 \\
0.77\end{array}$ & $\begin{array}{l}\text { Pass } \\
\text { Pass }\end{array}$ \\
\hline H51 & $\begin{array}{l}\text { Enterprise innovation--- } \\
\text { Technological innovation }\end{array}$ & 0.60 & Pass \\
\hline H52 & $\begin{array}{l}\text { Enterprise innovation--- Culture of } \\
\text { innovation management system }\end{array}$ & 0.68 & Pass \\
\hline H53 & $\begin{array}{l}\text { Enterprise innovation--- Marketing } \\
\text { Innovation }\end{array}$ & & \\
\hline H6 & $\begin{array}{l}\text { Enterprise products--- Enterprise } \\
\text { brand }\end{array}$ & $\begin{array}{l}0.63 \\
0.70\end{array}$ & $\begin{array}{l}\text { Pass } \\
\text { Pass }\end{array}$ \\
\hline $\mathrm{H} 7$ & $\begin{array}{l}\text { Enterprise products--- Corporate } \\
\text { image }\end{array}$ & $\begin{array}{l}0.64 \\
0.72\end{array}$ & $\begin{array}{l}\text { Pass } \\
\text { Pass }\end{array}$ \\
\hline $\begin{array}{l}\mathrm{H} 8 \\
\mathrm{H} 9\end{array}$ & $\begin{array}{l}\text { Enterprise brand--- Corporate image } \\
\text { Enterprise network--- Enterprise } \\
\text { innovation }\end{array}$ & & \\
\hline
\end{tabular}

\section{Conclusions}

Firstly, the research on the relationship between factors of textile and garment industry cluster brand through questionnaire design and data were analyzed, By AMOS17.0 final output structure we can draw that in the previous hypothesis of clusters brand are validated, The most relevant with textile and garment cluster brand is the innovation of enterprises in cluster, This innovative foregoing analysis is fundamentally consistent with the views of brand development. Secondly, the correlation between the cluster and the cluster within the enterprise network brand is relatively high, This shows that the development of cluster brand is different from the enterprise brand from one aspect. Clusters brand more emphasizes coordination of organization network and enterprise scale network development bring by organization network. this scale is one of the biggest difference between clusters and enterprise development.

As for the evaluation of the textile and garment industry cluster development, it can be combined with the output results of structure equation model, we can establish the textile and clothing industrial cluster brand evaluation index system, through structural equation correlation coefficients of each factor to determine the weight, And according to the fuzzy comprehensive evaluation model (formula) to quantify the textile and clothing industrial cluster brand evaluation. 
Textile and garment industry has a long history in Shanghai, It has a unique advantage in the textile and garment industry cluster brand development. Its brand business gradually stand more than $75 \%$ main business with the adjustment of Shanghai textile and garment industry bodies, Clusters create brand creative for Shanghai textile and garment industry cluster development has far-reaching significance especially in the current lack of cluster brand, In order to enhance the level and competitiveness of the industrial transformation of the industry and lay a solid foundation for the Shanghai textile and garment industry cluster brand development.

Of course, there have many shortcomings in this paper. Such as, the quantify of the factors just involves simple aspects, and there need further research on how to quantify and ensure measuring points.

\section{Acknowledgements}

This study was funded by Science Technology Commission of Shanghai Municipality, the funded project No.11510501600 and Municipal Education Commission of Shanghai, the funded project No.13ZS128.

\section{References}

Chen, J. (2007). Development strategy of modern industrial cluster. Pioneering with science and technology, 12, 71.

Gao, C. K, Hu, S. Z. (2013). The research on the development strategy of modern industry cluster for "Home Class Textile". Advanced Materials Research, 215-220. http://10.4028/www.scientific.net/AMR.796.215

George, A. (2007). Place branding: New tools for economic development. Design Management Review, 2, 60-68.

Lu,H.L, Zhou,Y, \& Tang, J.B. (2013). Influence factors of industrial cluster development. 2013 International Conference on Information Management, Innovation Management and Industrial Engineering. http://10.1109/ICIII.2013.6702914

Wu, J. X., Chen, J. X., Chen, L.H. (2011). To accelerate the transition to a modern industrial clusters upgrading. Zhejiang Economy, 20, 39.

Xu, Y. L, Wang, Q \& Wang, W. (2011). Fuyang paper industrial cluster performance evaluation based on fuzzy evaluation. 2011 International Conference on Electronics. http://10.1109/ICECC.2011.6068142

Zhao, J., Guo, B. (2013). Guo Hai industry clusters and enterprise brand interaction. Chinese soft science, 3, 149-160. 